\title{
Perception on Psychiatric Care Received by Patients Admitted Following Deliberate Self Harm to Three Hospitals in Galle District
}

Chandrasiri P.A.A. ${ }^{1^{*}}$, Gunethunga W. ${ }^{2}$ and Rajapakshe H. ${ }^{3}$

${ }^{1}$ Postgraduate Institute of Medicine, Colombo

${ }^{2}$ Faculty of Medicine, University of Colombo

${ }^{3}$ Faculty of Medicine, University of Ruhuna

\begin{abstract}
Deliberate Self-harm (DSH) adds a significant burden to the health care system in Sri Lanka. Delivering appropriate psychiatric care is crucial to minimize further risk. The objective of this study was to describe perception on psychiatric care received by patients who are admitted following DSH to selected hospitals in Galle District. Sample was taken from a large study which was intended to describe psychiatric management of patients admitted following DSH to 3 tertiary care hospitals in the Southern province of Sri Lanka. Only a sub-sample of 60 patients was taken for the analysis and it was further supplemented with a qualitative component. An interviewer-administered questionnaire (IAQ) was used and a series of in-depth interviews were also conducted. Descriptive statistics were calculated and qualitative data was analyzed separately. As per the results, only 22 (36.7\%) were referred to the psychiatry unit and the rest were discharged only after managing their medical problems. A majority (68.2\%) told that they were not informed about the need and importance of psychiatric referral. But a larger proportion mentioned that it was good (54.5\%) and it brought some relief to them (81.8\%). Only a few acknowledged that it helped them to solve their problems (22.7\%) and only a very few (13.6\%) told that they were embarrassed because of referring to the psychiatry unit. Out of those who had psychiatric referral, only 59.0\% were requested to attend for clinic follow up. But only $41.6 \%$ intended to come. Upon inquiring about their overall perception about psychiatric referral, almost all gave positive remarks. However, results of this study can be used a baseline and further studies are needed to confirm burden issue related to the health care system in Sri Lanka.
\end{abstract}

KEYWORDS - Deliberate Self Harm, Psychiatric Care 


\section{INTRODUCTION}

Self-harm adds a significant burden to the health care system in Sri Lanka as well as the personal suffering to the patients and families (Rajapakse, Christensen, Cotton, \& Griffith, 2016). Wickramasinge (2009), showed that the government of Sri Lanka spend nearly 0.9 million US dollars for treatment of DSH patients each year. Delivering appropriate psychiatric care following an attempt of Deliberate Self Harm (DSH) in the community is crucial to minimize further risk. Suicide prevention strategy in England recommends to follow up every case of DSH within seven days after discharge and active follow up if patient is missed from routine follow up (National Institute for Health and Clinical Excellence[NICE], 2004).

DSH survivors had 2-3 times higher risk of morality than expected morality rates and it was significantly higher among males than females. This also reiterated the importance of delivering good psychiatric care in hospital(Hawton, Zahl, \& Weatherall, 2003). Perception of patients towards psychiatric care they receive determines the compliance and uptake of management plan. A proper follow up plan should include measures to reduce further harm and to minimize other risk related behavior to improve quality of life and address other mental health conditions (NICE, 2004).

There is no category for DSH in Indoor Morbidity and Mortality Return (IMMR), which is the main source of hospital data in Sri Lanka and there is no surveillance system for DSH in hospital data flow. In a community based study Rajapakse, Griffiths, Christensen and Cotton (2015), found that the incidence of self-poisoning is 315 per 100,000. This indicated that there should be approximately 65000 episodes of self-poisoning should occur in Sri Lanka each year. When we apply the abovementioned extrapolation from completed suicides, it is assumed that 30000-90000 DSH acts are happening each year.

Though there were several studies done to describe the epidemiology of DSH in Sri Lanka, evidence are lacking on how patients perceive psychiatric care following DSH. The objective of this study was to describe perception on psychiatric care received by patients who are admitted following Deliberate Self Harm to selected hospitals in Galle District.

\section{METHOD}

The sample was taken from a large study which was intended to describe psychiatric management of patients admitted following DSH to 3 tertiary care hospitals which are located in the western half of the Southern province which is the heavily populated half which involved 392 subjects. Only a sub-sample of 60 patients, who were taken as the pre-intervention group of quasiexperimental component of the particular study was taken for analysis. The study was further supplemented with a qualitative component.

During the study, DSH was defined as an episode of intentional self-harm that did not lead to death which may or may not have been motivated by a desire to die(Gelder, Harrison, \& Cowen, 2006). All consecutive admissions to all study settings during the study period were recruited until the required sample size is reached. Patients who transferred out to other institutions or 
patients who died during the hospital stay were not included in the study.

An interviewer-administered questionnaire (IAQ) was developed to administer to the patients at the time of discharge. It consisted of items to assess the perception of patients about psychiatric management given in the hospital and degree of uptake of follow up plan in community. In addition to that a series of In-depth interviews were held with a sub sample of 10 to gather qualitative information. The sample was chosen by purposive sampling to represent a range of ideas. Ten was considered as an adequate sample to reach the saturation level. Both open ended and closed ended questions were included into a semi structured format. This allowed the interviewer to guide the interview well and be focused, but still let respondent to express his or her views freely. Closedended questions were included to obtain some specific information. Quantitative data was analyzed by using descriptive statistics and appropriate significant tests were applied where necessary. Qualitative data analysis was done by applying Giorgi's phenomenological method of analysis. First audio recordings of full conversations were transcribed into text. Then common themes were identified and grouped together to fit into the framework of study questions. Ethical approval was obtained from Ethics Review Committee at Faculty of Medicine, Ruhuna, Sri Lanka.

\section{RESULTS}

Majority of the sample were females $(n=33$, $55.0 \%$ ) and belong to $16-25$ years age category ( $n=33,55.0 \%)$. Most of them were not occupied $(\mathrm{n}=35,58.3 \%)$, reported a family income of Rs 30001-60000 ( $\mathrm{n}=28$, $46.7 \%$ ) and single ( $n=33,55.0 \%)$. Majority of the sample mentioned conflict in love affairs as the main precipitating factor ( $n=16,26.7 \%$ ) while drug overdose was the commonest method of self-harm $(n=34$, $56.7 \%)$.

Only 22 (36.7\%) subjects out of total sample were referred to the psychiatry unit and the rest were discharged only after being managed their medical problems. Awareness and perception of them about the psychiatric referral they received are described in the following table. 
Table 1: Description on Awareness and Perception of Patients about Psychiatric Referral

\begin{tabular}{|l|c|c|}
\hline \multirow{2}{*}{ Characteristic } & \multicolumn{2}{|c|}{ Participants } \\
\cline { 2 - 3 } & $\begin{array}{c}\text { Frequency } \\
(\mathrm{n}=22)\end{array}$ & $\begin{array}{c}\text { Percentage } \\
(100.0 \%)\end{array}$ \\
\hline Whether explained/advised about the need and importance of & & \\
psychiatric referral & 6 & 27.3 \\
Yes & 15 & 68.2 \\
No & 1 & 4.5 \\
\hline Can't remember & & 54.5 \\
\hline Perception about psychiatric referral & 12 & 13.6 \\
It was good & 3 & 31.8 \\
There was no point & 7 & 81.8 \\
No idea & & 9.1 \\
\hline Whether it brought some relief to the patient & 18 & 9.1 \\
Yes & 2 & \\
No & 2 & 22.7 \\
No idea & & 22.7 \\
\hline Whether it solved problems of patient & 5 & 54.5 \\
Yes & 5 & \\
No & 12 & 13.6 \\
No idea & & 81.8 \\
\hline Whether patient was embarrassed & 3 & 4.5 \\
Yes & 18 & \\
No & 1 & \\
No idea & & \\
\hline
\end{tabular}

Majority of them ( $n=15,68.2 \%)$ told that they were not informed about the need and importance of psychiatric referral. But a larger proportion mentioned that it was good $(n=12,54.5 \%)$ and it brought some relief to them $(n=18,81.8 \%)$. Only a few acknowledged that it helped them to solve their problems $(n=5,22.7 \%)$ and only a very few $(n=3,13.6 \%)$ told that they were embarrassed because of referring to the psychiatry unit.

Out of those who had psychiatric referral only 13 (59.0\%) were requested attend for clinic follow up. Among them $(n=12$, 92.3\%) mentioned that they were explained about the importance of clinic visit but only $41.6 \%(n=5)$ intended to come. Only in
$60 \%(n=6)$ of patients the carer was informed about clinic referral. Out of them $66.6 \%(n=4)$ mentioned that they intend to bring the patient to the clinic.

By the time of discharge, only $26.7 \%$ $(n=16)$ has accepted that they received support from the hospital staff to solve problems while majority $(n=37,61.7 \%)$ had no idea on that. Only one patient (1.7\%) was given contact details of person/institute to seek help. But more than half of the population ( $n=34,56.7 \%)$ mentioned that they can identify a person to seek help when they are in trouble. But only two subjects (3.3\%) mentioned that they can identify an institute to seek help when they are in trouble now. Out of 34 people who 
mentioned that they can identify a person to seek help when they are in trouble, 30 (88.2\%) told that they will seek help from that particular person when they get a trouble next time. Results are presented in following table.

Table 2: Description of Current Status of Receiving Help and Of Ability to Seek Help Among Participants

\begin{tabular}{|l|c|c|}
\hline \multirow{2}{*}{ Characteristic } & \multicolumn{2}{|c|}{ Participants } \\
\cline { 2 - 3 } & $\begin{array}{c}\text { Frequency } \\
(\mathrm{n}=60)\end{array}$ & $\begin{array}{c}\text { Percentage } \\
(100.0 \%)\end{array}$ \\
\hline Whether received support from hospital staff to solve problems & & \\
Yes & 16 & 26.7 \\
No & 7 & 11.7 \\
No idea & 37 & 61.7 \\
\hline Whether patient was given contact details of person/institute to & & \\
seek help & 1 & 1.7 \\
Yes & 55 & 91.6 \\
No & 3 & 5.0 \\
Can't remember & 1 & 1.7 \\
Missing & & \\
\hline Whether patient can identify a person to seek help when they & 34 & 56.7 \\
are in trouble & 16 & 26.7 \\
Yes & 10 & 16.7 \\
No & & \\
No idea & 2 & 3.3 \\
\hline Whether the patient can identify an institute/service to seek & 58 & 96.7 \\
help when they are in trouble & 0 & 0.0 \\
Yes & & \\
No & & \\
No idea & & \\
\hline
\end{tabular}

A larger proportion of subjects $(\mathrm{n}=45$, 75.1\%) acknowledged that they are not expecting any problems in re-engaging with normal routine. More than $90 \%$ of subjects gave positive expectations as they didn't expect any problems in re-engaging with family ( $\mathrm{n}=55,91.7 \%)$ and re-engaging with friends and relatives ( $\mathrm{n}=56,93.3 \%)$.

Only 49 subjects could be taken for analysis since relatives of remaining patients were not available at the time of discharge. Majority of them ( $n=31,64.6 \%)$ mentioned that they were explained on how to help/take care of the patient after returning home. But a very few told that they were explained on how to respond if the patient makes another attempt $(\mathrm{n}=3$, $5.2 \%)$ and only one $(n=1,2.1 \%)$ informed about contact details of any person/institute to seek help.

In depth interviews were performed to obtain qualitative information pertaining to the Perception on psychiatric care received by patients. 
Upon inquiring about their perception on psychiatric referral almost all the patients who were referred to psychiatry unit gave positive remarks.

Matrix 1: Key themes pertaining to perception on psychiatric referral

- Almost everyone accepted psychiatric referral as a good thing. Specifically they appreciated the opportunity of being listened their worries by someone.

- However as mentioned in the above chapter how they utilized them to solve their true problems and how they related the psychosocial interventions to specific problems they had were difficult to elicit.

- But some of the patients felt embarrassed and stigmatized because of the referral.

Appreciation of the opportunities to get their worries listened by someone was emerged as a common theme. Many of the subjects who were seen by psychiatric team also valued the advices they received.

However embarrassment was also a common feeling reported by most of the subjects. There were few apparent themes behind this. Sending to psychiatry ward gave them the idea of being psychiatrically ill. On the other hand they worried of what others may think.

\section{DISCUSSION AND CONCLUSION}

Study was carried out in three hospitals namely; TH Karapitiya, BH Balapitiya and BH Elpitiya. As described in the methodology these three hospitals were chosen because nearly $80 \%$ of the in-ward admissions in Galle district drain to these three hospitals(Provincial Director of Health Services Southern, 2014).

Out of those who were referred to psychiatric unit only $27.3 \%$ were explained about the need and importance of psychiatric referral. Not making patients adequately aware on the importance of psychiatric referral was the main reason behind high rates of leaving against medical advice during the gap of making the referral and seen by the psychiatry team. Therefore this should be addressed in subsequent interventions to improve psychiatric care of DSH patients.

But majority of patients perceived that the psychiatric referral is important. A larger proportion mentioned that it was good (54.5\%) and it brought some relief to them (81.8\%). The opportunity they had of being listened their worries by someone was repeatedly appreciated during IDI's. But only $22.7 \%$ mentioned that it was helped in solving the particular problem the patient had. Majority (54.5\%) had no idea whether it specifically solved their problems. This was also elicited during IDI's. Only few attributed the resolution of problems to care they received in hospital. It means that, there is a gap exists between expectation of patients and psychiatric care being delivered, with respect to addressing the particular problems they had. 
Only $13.6 \%$ mentioned that they were embarrassed when referring to psychiatry unit. Though the number was small, embarrassment of patients due to psychiatric referral should be addressed seriously. Because it adversely influence the compliance with care. Two main themes were elicited during IDI's as reasons. Sending to psychiatry ward gave them the idea of being psychiatrically ill. On the other hand they worried of what others may think. In Sri Lankan society psychiatric illnesses are stigmatized by people. This leads to the reluctance of people seeking psychiatric care. Because of that they worry what others may think if they are observed by others while attending psychiatric services. According to the service delivery system some patients are summoned to the psychiatric ward for assessment. This was disliked by some patients as revealed in IDI's.

Though the perceived mental status appeared to be good when starting IDI's, when inquiring into depth and rapport was developed it was clearly seen that the actual situation was not so. Even though they said 'I'm fine', their facial expressions were not convincing in most instances. It's natural that people are willing to acknowledge that they are free of problems at the beginning, when directly inquired by someone.

Among those the manipulative motives were succeeded, almost all committed the act following relationship issues. It doesn't indicate the true resolution of problem. It just showed succession of manipulative motive of the patient.

Though many of the medical staff were willing to support these patients, lack of competency arise as a barrier. In most instances they were given generic advices, not focus to the particular problem they had. Emphasizing the importance of education and suggesting to forget previous love affairs were common content in most of the advices as revealed in IDI's. Feeling sympathy and seen only the surface of the problem were appeared.

\section{ACKNOWLEDGEMENT}

Director, Teaching Hospital Karapitiya and Medical Superintends of all the hospitals where the study was conducted for permitting us to conduct the study with fullest blessings. All the medical staff in wards of all three study settings for extending their support

This study was received a research grant from Education, training and research unit of Ministry of Health.

No conflicts of interests

\section{REFERENCES}

Gelder, M., Harrison, P., \& Cowen, P. (Eds.). (2006). Shorter Oxford Textbook of Pshychiatry (6th ed.): Oxford Universiry Press.

Hawton, K., Zahl, D., \& Weatherall, R. (2003). Suicide following deliberate selfharm: long-term follow-up of patients who presented to a general hospital. The British Journal of Psychiatry, 182(6), 537-542. doi: 10.1192/bjp.182.6.537

National Institute for Health and Clinical Excellence[NICE]. (2004). Self-harm: The Short term Physical and Psychological Management and Secondary Prevention of 
Self-harm in Primary and Secondary Care:

National Institute for Health and Clinical Excellence

Provincial Director of Health Services Southern. (2014). Annual Health Bulletin. Galle: Provincial Director of Health Services.

Rajapakse, T., Christensen, H., Cotton, S., \& Griffith, K. (2016). Non-fatal selfpoisoning across age groups, in Sri Lanka. Asian Journal of Psychiatry, 19, 79-84. 